\title{
A Numerical Investigation of Co-flow Jet Effects on Airfoil Aerodynamic Characteristics
}

\section{Shima Yazdani}

Quchan University of Technology

Erfan Salimipour ( $\nabla$ erfan.salimipour@gmail.com )

Quchan University of Technology https://orcid.org/0000-0003-2077-0566

\section{Ayoob Salimipour}

Quchan University of Technology

\section{Original Article}

Keywords: Numerical solution, Co-Flow Jet (CFJ), Stall, Aerodynamic characteristics, Momentum coefficient

Posted Date: July 7th, 2021

DOI: https://doi.org/10.21203/rs.3.rs-672095/v1

License: @ (i) This work is licensed under a Creative Commons Attribution 4.0 International License. Read Full License 


\title{
A numerical investigation of co-flow jet effects on airfoil aerodynamic characteristics
}

\author{
Shima Yazdani ${ }^{1}$, Erfan Salimipour ${ }^{1 *}$, Ayoob Salimipour ${ }^{2}$ \\ ${ }^{I}$ Department of Mechanical Engineering, Quchan University of Technology, Quchan, Iran \\ ${ }^{2}$ Department of Mathematics, Quchan University of Technology, Quchan, Iran \\ *Corresponding author, Email: esalimipour@qiet.ac.ir
}

\begin{abstract}
The present paper numerically investigates the performance of a Co-Flow Jet (CFJ) on the static and dynamic stall control of the NACA 0024 airfoil at Reynolds number $1.5 \times 10^{5}$. The two-dimensional Reynolds-averaged Navier-Stokes equations are solved using the SST $k$ - $\omega$ turbulence model. The results show that the lift coefficients at the low angles of attack (up to $\alpha=15^{\circ}$ ) are significantly increased at $C_{\mu}=$ 0.06 , however for the higher momentum coefficients, it is not seen an improvement in the aerodynamic characteristics. Also, the dynamic stall for a range of $\alpha$ between $0^{\circ}$ and $20^{\circ}$ at the mentioned Reynolds number and with the reduced frequency of 0.15 for two CFJ cases with $C_{\mu}=0.05$ and 0.07 are investigated. For the case with $C_{\mu}=0.07$, the lift coefficient curve did not present a noticeable stall feature compared to $C_{\mu}=$ 0.05 . The effect of this active flow control by increasing the Reynolds numbers from $0.5 \times 10^{5}$ to $3 \times 10^{5}$ is also investigated. At all studied Reynolds numbers, the lift coefficient enhances as the momentum coefficient increases where its best performance is obtained at the angle of attack $\alpha=15^{\circ}$.
\end{abstract}

Keywords: Numerical solution; Co-Flow Jet (CFJ); Stall; Aerodynamic characteristics; Momentum coefficient.

\section{Nomenclature}

$\begin{array}{llll}c & \text { Airfoil chord length } & u, v & \text { Cartesian velocity components } \\ C_{d} & \text { Drag coefficient } & \alpha & \text { Angle of attack } \\ C_{l} & \text { Lift coefficient } & \mu & \text { Dynamic viscosity } \\ C_{p} & \text { Pressure coefficient } & \mu_{t} & \text { Turbulent viscosity } \\ C_{\mu} & \text { Momentum coefficient } & \rho & \text { Density } \\ p & \text { Pressure } & - & \text { Mean value superscript } \\ \operatorname{Re} & \text { Reynolds number } & \infty & \text { Free-stream subscript } \\ U_{\infty} & \text { Free-stream velocity } & & \end{array}$




\section{Introduction}

Wind turbines are used to convert the wind's kinetic energy into electrical energy and are categorized into two main types of vertical axis and horizontal axis. Generally, although horizontal-axis wind turbines (HAWT) are popular all around the world, they cannot be used in municipal areas, damage the environment, and need a high initial cost. Wind energy is considered as one the cheapest and most available renewable energy resources. However, due to different problems of HAWTs, wind turbines are not widely employed. Thus, vertical-axis wind turbines (VAWT) take on paramount importance [1]. The most important superiority of this type of wind turbines is that they do not need to be adjusted relative to the wind direction. Regarding that the axis is vertical, gearbox and generator can be installed near the ground leading to facilitating the maintenance and repair of these pieces of equipment. Since the blade tip is closer to the rotating axis in VAWTs, in comparison to HAWTs, they make lower noise. Furthermore, due to the smaller size of them, the peripheral collisions are reduced. NACA airfoils are designed for aircraft and wind turbines. Investigating airfoil characteristics, particularly in incompressible low-Reynolds flows, and changes in aerodynamic performance of airfoils, due to the amount of the Reynolds number, is of paramount importance. Several investigations were conducted to study the performance of airfoils in low Reynolds number region [2-4]. Some studies indicated that for below Reynolds number of about 500,000 the flow has not a specific behavior and serious aerodynamic problems maybe occur [5-7]. In this range of Reynolds number, the trend of flow in suction surface of the airfoil is to be separated. On the other hands, the reverse pressure gradient that occurs in low Reynolds number airfoils causes the flow separation [8]. As the angle of attack increases, the vertical velocity and, consequently, the lift coefficient are escalated. Furthermore, since the vertical velocity depends on the air resistance, the drag coefficient is also enhanced. This 
trend continues up to a specific angle, called the stall angle. When stall happens, devastating effects on aerodynamic performance occur; the lift coefficient dramatically decreases while the drag coefficient continues to increase $[9,10]$. Thus, applying methods to control the stall phenomenon and control the separation flow is of great importance. The airfoil aerodynamic performance can be enhanced, with the adequate energy and momentum transported to the boundary layer using flow control methods, in order to reach desired aerodynamic goals including delaying the transition, delaying the separation, and improving the aerodynamic efficiency. To control the flow separation and prevent the consequences of that, many effective methods presented so far [11-16]. In aerodynamics with low Reynolds number, the change of airfoil geometry is usually used to control the separation and improve the lift coefficient. One of the active flow control techniques is Co-Flow Jet (CFJ) that developed by Zha et al. [17, 18]. In this technique, there are two slots on the suction surface of the airfoil, an injection slot near the leading edge, and a suction slot near the trailing edge. The whole process does not add any mass flow to the system and hence is a zero-net mass flux flow control and the energy loss are minimized. Use of suction and injection in the airfoil surface especially at the high angles of attack, with resistance to the reverse pressure gradient makes the main flow to be attached and they both enhance the boundary-layer momentum. The suction slot helps to achieve zero net mass flow rate of the jet. Zha et al. [17] in wind tunnel investigated the effects of injection slot size on the NACA 0025 at Reynolds number Re $=3.8 \times 10^{5}$. Their result presented that to increase the stall margin and maximum lift the smaller injection slot size airfoil is more efficient whereas, to reduce drag the larger slot is more useful. Zha et al. [19] numerically investigated the effect of the suction slot on the efficiency of the CFJ. For this purpose, two airfoils with the same injection slot $(0.65 \% c)$ studied that one of them with the suction slot equal to $1.96 \% c$ and the other without the suction slot. This study showed that the airfoil with the 
suction slot had better aerodynamic performances. For both airfoils compare the baseline airfoil, the lift coefficient increased and the angle of attack was delayed. The airfoil without a suction slot the stall occurred at $39^{\circ}$ and the other until $43^{\circ}$ the stall did not happen. Zha and Gao [20] experimentally performed the effects of the CFJ on the NACA 0025 at Reynolds $3.8 \times 10^{5}$. They examined several pressure ratios, and their results showed that the lift coefficient of the CFJ compared to baseline increased by $220 \%$. They also numerically performed their experimental results and there was a good agreement between the data for the lift coefficient. However, the angle of attack of the stall was forecasted in numerical results 3 degrees more than experiments. Wells et al. [21] experimentally investigated the size changes of the injection slot on the lift coefficient, drag coefficient, and angle of stall occurrence. Their result showed to achieve the equivalent lift coefficient, an airfoil with a smaller injection slot will consume less energy from the airfoil with a larger injection slot. Chng et al. [22] experimentally studied the performance of the CFJ concept as applied to a Clark-Y airfoil. Furthermore, they prepared a comparison between the aerodynamic performance of the CFJ, pure injection, and pure suction. Their results showed that the CFJ is more effective, compared pure injection and pure suction. Abinav et al. [23] by using ANSYS FLUENT conducted a comparison of the performance of NACA 6409 baseline airfoil and the three CFJ airfoils with varying positions of injection and suction slots. Xu et al. [24] numerically investigated the effect of CFJ on the S809 airfoil at three jet momentum coefficient levels. Their result indicated that the CFJ significantly decrease the drag coefficient and has a positive effect in increasing the lift and stall margin. Ethiraj [25] numerically investigated on effect of CFJ and his result for angle of attack of $12^{\circ}$ shows $25-30$ percent reduction in drag and 10-20 percent increase in lift coefficient. Siddanathi [26] used CFJ on NACA 652-415 airfoil to investigated this active flow control on increasing the lift. Mirhosseini and Khoshnevis [27] experimentally investigated the effect of CFJ 
on the boundary layer and provided valuable information about the adverse pressure gradient. Their result showed the CFJ can overcome the adverse pressure gradient at angle higher than $12^{\circ}$. Amzad Hossain et al. [28] experimentally studied the baseline NACA 0015 airfoil and CFJ0015065-065 to investigate and compare the airfoil aerodynamic characteristics over a wide range of angles of attack with free stream velocity of $12 \mathrm{~m} / \mathrm{s}, \operatorname{Re}=1.89 \times 10^{5}$, and $C_{\mu}=0.07$. Their result showed the CFJ airfoil compare to the baseline airfoil $C_{L \text { max }}$ increased by $82.5 \%$ and the drag decreased by $16.5 \%$ at stall angle of attack. Lefebvre and Zha [29] numerically studied the effect of CFJ flow control on a pitching airfoil at the Reynolds number of $3.93 \times 106$ and reduce frequency between 0.05 and 0.2. Moreover, $\mathrm{Xu}$ et al. [30] simulated the dynamic stall phenomenon for a wind turbine blade using the CFJ.

In the present paper, an active flow control on the NACA 0024 airfoil defined as co-flow jet $(\mathrm{CFJ})$ at the chord-based Reynolds number of $1.5 \times 10^{5}$ is studied. The two-dimensional incompressible unsteady Reynolds-Averaged Navier-Stokes equations with the SST $k$ - $\omega$ turbulence model is utilized to study the effects of CFJ on the aerodynamic characteristics of the static and dynamic stall phenomena. The implementation of the CFJ is conducted with several momentum coefficients to investigate the turnover of them. Moreover, the present paper is aimed to evaluate the CFJ performance by changing the Reynolds number and jet momentum coefficient and compare all the states with the baseline airfoil which has not been investigated in the previous research studies.

\section{Model Description}

The CFJ is constructed at the suction surface of the baseline NACA 0024 airfoil to produce a jet tangential to the main-flow; the heights of an injection slot and a suction slot are considered 0.006 and 0.019 times the chord length, respectively. The injection and suction slots are located at 
distances of 0.07 and 0.83 times the chord length from the leading edge, respectively. Based on the considered geometry, various meshing strategies can be employed where we choose a "C" grid to solve the flow using the elliptic method. Fig. 1 shows a close-up view of this grid together with the situation of a CFJ on the airfoil. As it can be observed, the nodes possess an appropriate perpendicular to one another.
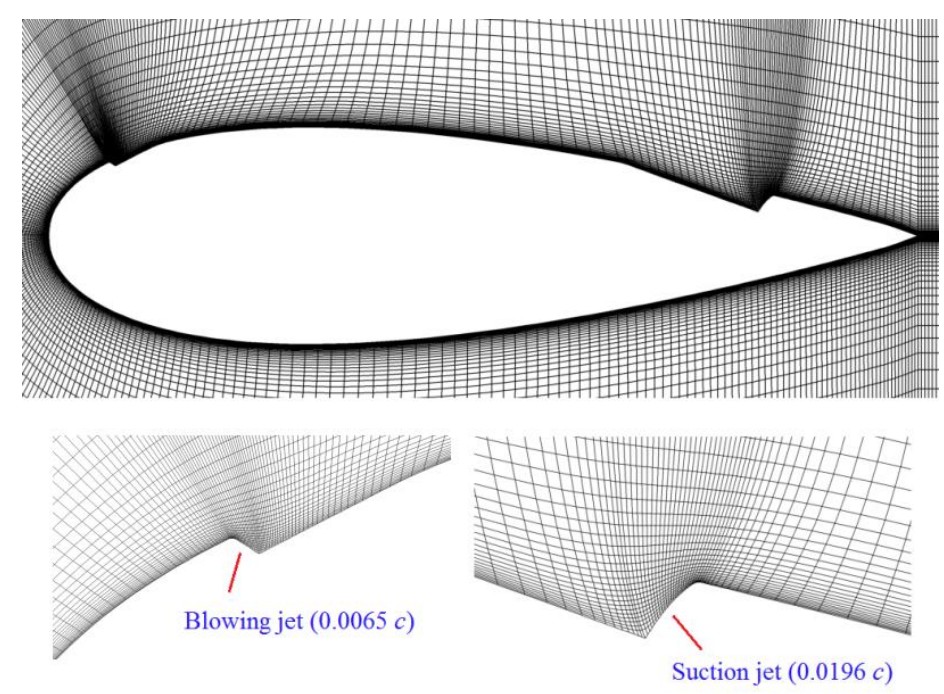

Fig. 1 The grid used in flow computations and situation of the CFJ on the airfoil.

Fig. 2 shows the computational domain and applied boundary conditions. The velocity inlet boundary includes a constant value of $U_{\infty}$ for the horizontal velocity component, zero for the vertical velocity component and a zero normal gradient for the pressure [31]. On the pressure outlet boundary, a fixed value of $p_{\infty}$ is applied for the pressure and the normal gradient of the velocities are set to zero. On the solid wall, a no slip boundary condition is considered. 


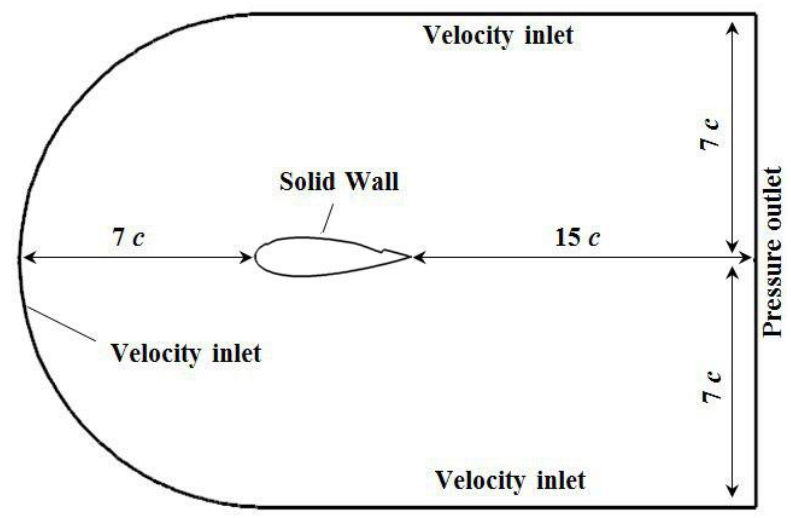

Fig. 2 Computational domain and applied boundary conditions around the NACA 0024 airfoil.

\section{Mathematical and Numerical Formulation}

The integral formulations of the Reynolds-averaged Navier-stokes equations including the continuity and momentum can be written as follows [32]:

$$
\begin{aligned}
& \oint_{\partial \Omega} \rho V d S=0 \\
& \frac{\partial}{\partial t} \int_{\Omega} \vec{W} d \Omega+\oint_{\partial \Omega} \vec{J} d S=0
\end{aligned}
$$

where $\rho$ denotes the density, $\Omega$ is a volume surrounded by the control surface $\partial \Omega, V$ is the velocity perpendicular to the surface element $d S, \vec{W}$ denotes the conservative variables vector, and $\vec{J}$ consists of the convective and diffusive fluxes which can be written as follows [7]:

$$
\begin{aligned}
& \vec{W}=\left[\begin{array}{l}
\rho u \\
\rho v
\end{array}\right], \quad \vec{J}=\left[\begin{array}{l}
\rho u V+n_{x} p-\left(\mu+\mu_{t}\right)\left(n_{x} \frac{\partial u}{\partial x}+n_{y} \frac{\partial u}{\partial y}\right) \\
\rho v V+n_{y} p-\left(\mu+\mu_{t}\right)\left(n_{x} \frac{\partial v}{\partial x}+n_{y} \frac{\partial v}{\partial y}\right)
\end{array}\right], \\
& V \equiv \vec{v} \cdot \vec{n}=n_{x} u+n_{y} v
\end{aligned}
$$

where $\mu$ and $\mu_{t}$ denote the laminar and turbulent viscosity, respectively. The flow equations (1) and (2) are solved by a pressure-based method proposed by Rajagopalan and Lestari [33]. The momentum equation is discretized with second-order temporal and special accuracy. Furthermore, the pressure equation is numerically solved using a Strongly Implicit procedure (SIP) developed 
by Stone [34]. In order to simulate the turbulent viscosity $\left(\mu_{t}\right)$, the $S S T k-\omega$ turbulence model is used. The flow variables are normalized as express in [35].

By solving the above-mentioned equations numerically, the required flow parameters such as pressure and velocity components are computed, and then, the streamlines and the drag and lift coefficients can be obtained. The jet momentum coefficient $C_{\mu}$ is a parameter used to measure the jet intensity. It is defined as follow [16]:

$$
C_{\mu}=\frac{\dot{m} U_{j}}{1 /{ }_{2} \rho_{\infty} U_{\infty}^{2} c}
$$

where $\dot{m}$ is the injection mass flow, $U_{j}$ the injection velocity, $\rho_{\infty}$ and $U_{\infty}$ denote the free stream density and velocity, respectively and $c$ is the airfoil chord length. For cases with a CFJ on, the total aerodynamic force is computed according to the analysis in Ref. [19, 24]. The total lift and drag coefficients can be expressed as follows:

$$
\begin{aligned}
& C_{l}=C_{l, \text { pressure }}+C_{l, \text { stress }}+C_{l, j e t} \\
& C_{d}=C_{d, \text { pressure }}+C_{d, \text { stress }}+C_{d, \text { jet }}
\end{aligned}
$$

where subscripts pressure, stress and jet indicate the pressure force, frictional force and jet mass flow thrust, respectively. $C_{l, p r e s s u r e+s t r e s s}$, and $C_{d, p r e s s u r e+s t r e s s}$ can be calculated by standard integral algorithm in the solver, while $C_{l, j e t}, C_{d, j e t}$ are achieved using relations as follows:

$$
\begin{aligned}
& C_{l, j e t}=\frac{\dot{m}_{j}\left(\vec{V}_{j 1}-\vec{V}_{j 2}\right) \vec{j}}{1 /{ }_{2} \rho_{\infty} U_{\infty}^{2} c} \\
& C_{d, j e t}=\frac{\dot{m}_{j}\left(\vec{V}_{j 1}-\vec{V}_{j 2}\right) \vec{\imath}}{1 / 2 \rho_{\infty} U_{\infty}^{2} c}
\end{aligned}
$$


where $(\vec{\imath}, \vec{\jmath})$ is the unit vector representing the drag and lift direction and $\vec{V}_{j 1}, \vec{V}_{j 2}$ are the jet velocity vectors at injection and suction slot, respectively.

The pitching motion of the airfoil for dynamic stall analysis is described by the following equation:

$$
\alpha(t)=10^{\circ}+10^{\circ} \sin (2 k \tau)
$$

where $k=\omega c / 2 U_{\infty}$ is the reduced frequency and $\tau=t U_{\infty} / c$ denotes the non-dimensional time.

For quantifying the improvement of the results from the CFJ to enhance the lift and decrease the drag coefficients for the dynamic stall study, the differences in the area under the $C_{l}$ and $C_{d}$ curves between the control cases and the baseline airfoil are calculated. This is accomplished as follows (where $q$ is either lift or drag):

$$
\Delta A_{C_{q}}=\frac{\int_{0}^{2 \pi}\left(C_{q}^{\text {baseline }}-C_{q}^{C F J}\right) d \varphi}{\int_{0}^{2 \pi} C_{q}^{\text {baseline }} d \varphi}
$$

where $\varphi$ denotes the phase angle of the pitching motion in radians.

In order to compare the results of the CFJ airfoil with the baseline airfoil, three performance parameters are used defined as follows:

$$
\begin{aligned}
& \eta\left(C_{l}\right)=\left|\frac{C_{l_{C F J}}-C_{l_{\text {Baseine }}}}{C_{l_{\text {Baseine }}}}\right| \times 100 \\
& \eta\left(C_{d}\right)=\left|\frac{C_{d_{C F J}}-C_{d_{\text {Baseine }}}}{C_{d_{\text {Baseine }}}}\right| \times 100 \\
& \eta\left(C_{l} / C_{d}\right)=\left|\frac{C_{l} / C_{d_{C F J}}-C_{l} / C_{d_{\text {Baseine }}}}{C_{l} / C_{d_{\text {Baseine }}}}\right| \times 100
\end{aligned}
$$




\section{Results and Discussion}

\subsection{Grid resolution study}

In order to investigate the grid independency of the computational domain, meshes with different numbers of cells were evaluated and their results were compared with each other. As shown in Fig. 3 three grids with 25000, 30000 and 38000 cells were tested. This comparison of pressure coefficients of the CFJ by the mentioned grids was performed at $\operatorname{Re}=1.5 \times 10^{5}, \alpha=15^{\circ}$ and $\mathrm{C}_{\mu}=$ 0.13. The results for 30000 and 38000 cells were very similar. In this study, the grid with $\mathbf{N}=$ 38000 cells was selected for the conducted computations.

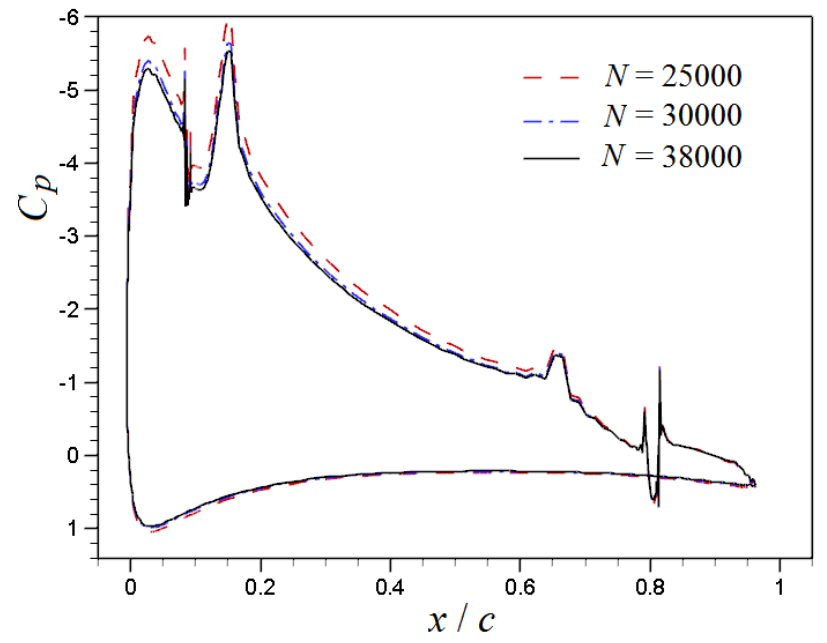

Fig. 3 Comparison of pressure coefficients of CFJ airfoil with different computational grids at $\operatorname{Re}=1.5 \times 10^{5}, \alpha=15^{\circ}$ and $C_{\mu}=0.13$.

\subsection{Code validation study}

Before using the written code and in order to validate its accuracy, it is necessary to test the validity of the flow solver. Experimental data obtained by Zha et al. [17] used to evaluate the solver ability, for the configuration of NACA 0025 and CFJ0025-65-196 at Reynolds number of $3.8 \times 10^{5}$. Fig. 4 
shows the comparison of the lift to drag ratio between the present solver and experimental data. The prognostications are in nearby conjunction with the experimental data [17].

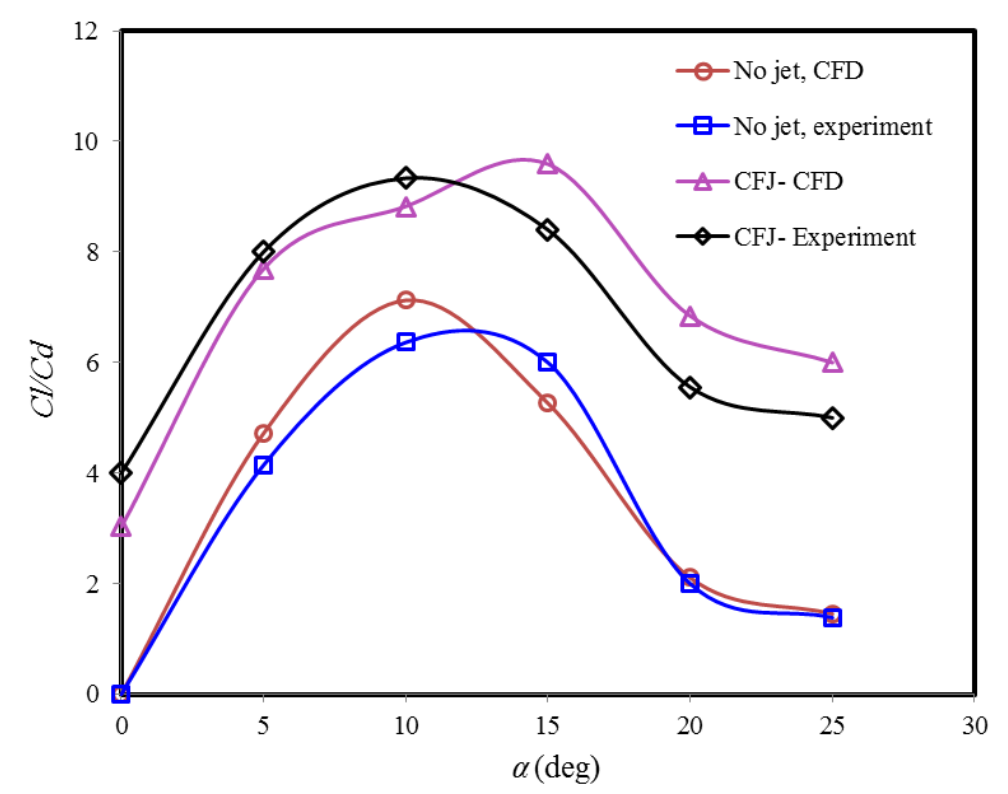

Fig. 4 Comparison of $C_{l} / C_{d}$ between the present solver and experimental data [17].

\subsection{Effect of momentum coefficient of CFJ on static stall at Re $=1.5 \times 10^{5}$}

In this study, several momentum coefficients $\left(C_{\mu}\right)$ for the angles of attack in range of 0 - 30 degrees at $\operatorname{Re}=1.5 \times 10^{5}$ on the NACA 0024 airfoil are investigated to understand which momentum coefficient has an agreeable performance at each angle of attack. Fig. 5 shows the streamlines and the contours of the pressure coefficients for the baseline geometry at the angles of attack $\alpha=5^{\circ}$, $10^{\circ}, 13^{\circ}$ and $15^{\circ}$. The growth and shedding of the vortices can be seen for $\alpha \geq 10^{\circ}$. 


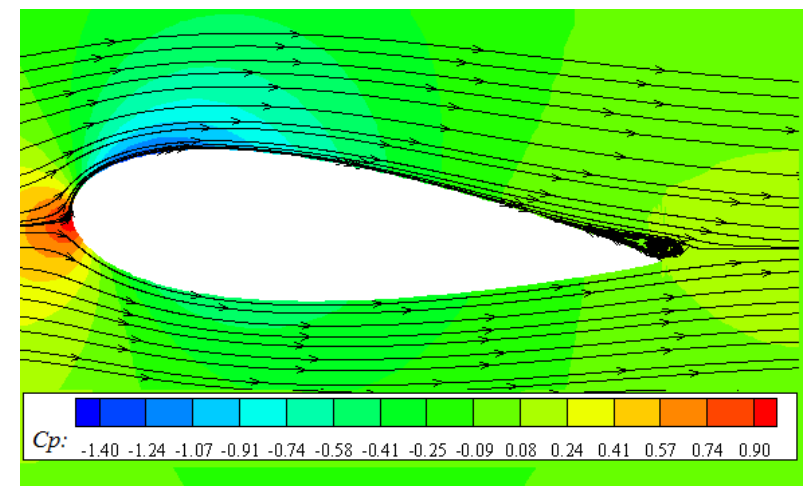

(a)

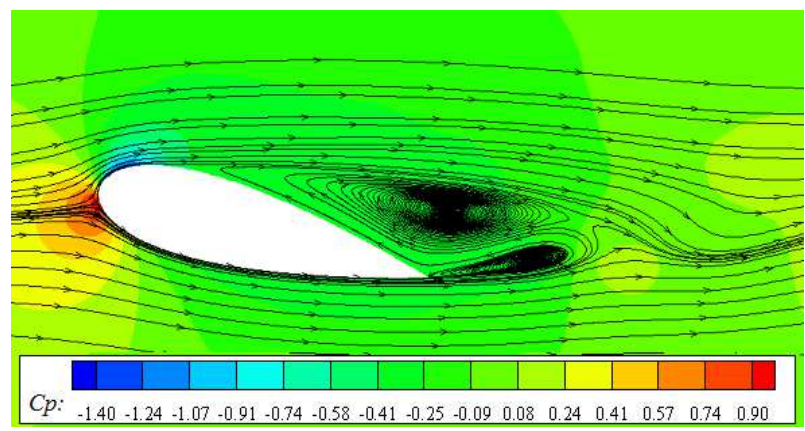

(c)

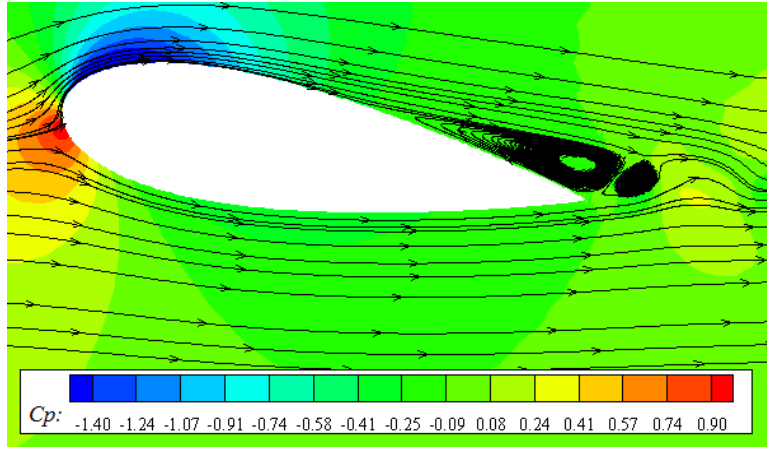

(b)

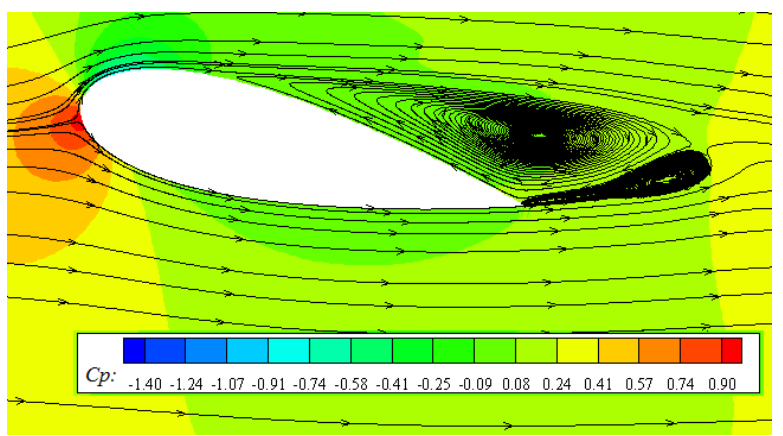

(d)

Fig. 5 Streamlines and pressure coefficient contours at several angles of attack for baseline geometry, (a) $\alpha=5^{\circ}$, (b) $\alpha=10^{\circ}$, (c) $\alpha=13^{\circ}$, (d) $\alpha=15^{\circ}$.

Fig. 6 shows the streamlines around the CFJ airfoil with $C_{\mu}=0.05$ at $\alpha=15^{\circ}$. By applying the CFJ, the vortices on the airfoil is removed. Actually, the CFJ injects a momentum into the boundary layer which can resist the flow separation due to the adverse pressure gradient.

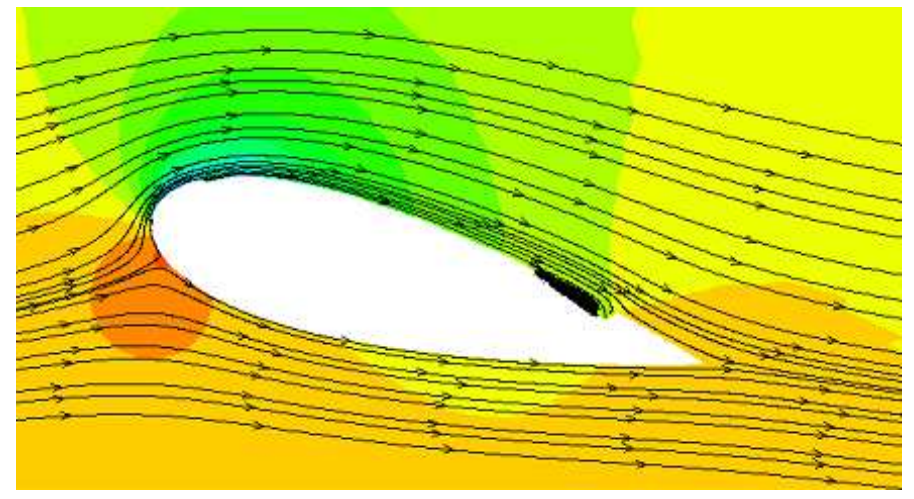

Fig. 6 Streamlines and pressure coefficient contours for CFJ geometry at $\alpha=15^{\circ}$ and $C_{\mu}=0.05$. 
Fig. 7 shows a comparison between the pressure coefficient distributions of the baseline and CFJ airfoils at $\alpha=15^{\circ}$ and $C_{\mu}=0.05-0.13$. The spikes in the plots are due to the jet inlet and outlets. The comparisons show that the CFJ airfoils have a significantly higher suction peak near the leading edge than the baseline airfoil. This effect leads to increase in the lift and decrease in the pressure drag of the airfoil. The maximum absolute value the pressure coefficient is 5.6 at $C_{\mu}=$ 0.13, while for the baseline airfoil, it is 1.5 . Fig. 8 shows the time variations of the lift coefficients for baseline and CFJ airfoils with different momentum coefficients at $\alpha=15^{\circ}$. It can be seen that all the curves finally become unchanged over the time and thus, the flow at this angle of attack has been steady. Furthermore, the trend of the baseline airfoil curve indicates that the stall occurs in this angle of attack, unlike the other curves.

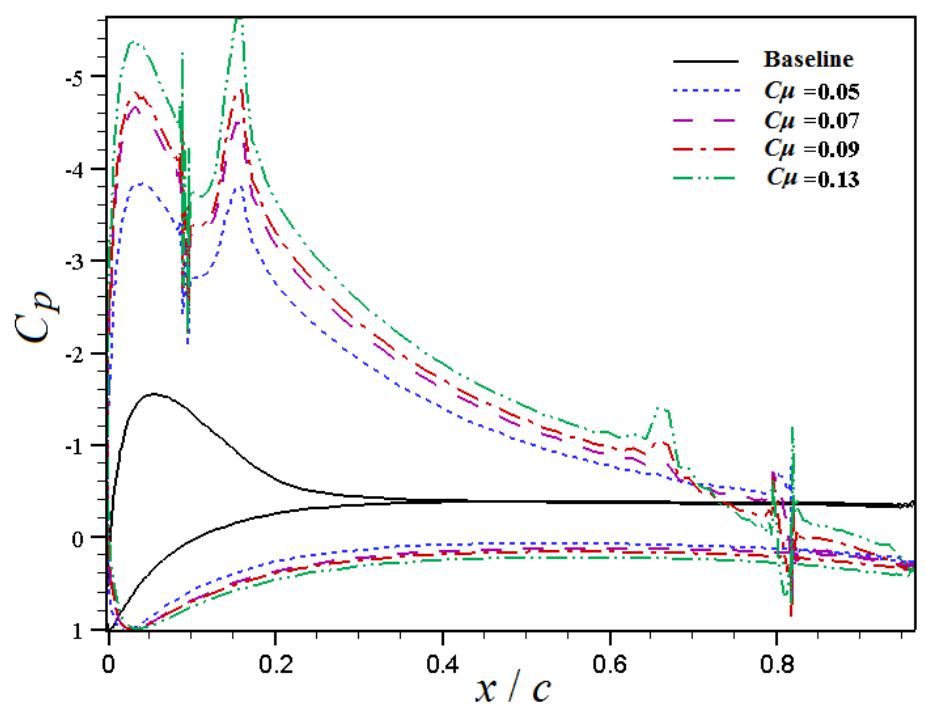

Fig. 7 Comparison of the pressure coefficient distributions at $\alpha=15^{\circ}$ for different $C_{\mu}$ levels. 


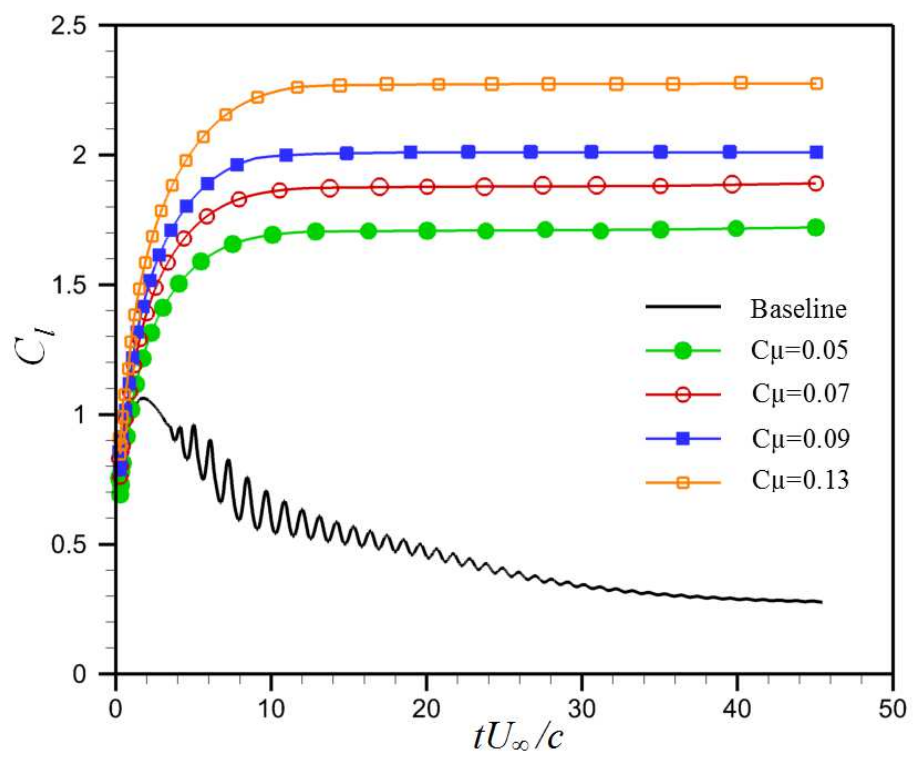

Fig. 8 Temporal variations of lift coefficients at $\alpha=15^{\circ}$ for different $C_{\mu}$ levels.

One of the important parameters for the aerodynamic performance of aircraft is the lift to drag ratio. Fig. 9 shows the lift to drag coefficient curves with respect to angle of attack for several momentum coefficients. The CFJ airfoils compared to the baseline airfoil, have a dramatic gain in the lift to drag coefficients and causes the stall occurs at the higher angles of attack maintained with higher values of $C_{\mu}$. As can be seen, for all of the CFJ airfoils with various momentum coefficients, the stall angles and maximum lift to drag coefficients are increased with raising the momentum coefficient. The lift to drag coefficient diagram shows that for the CFJ airfoil with $C_{\mu}$ $=0.05$, there is a significant increase for the $C_{l} / C_{d}$ and the stall angle is delayed, compared to the baseline airfoil. At $C_{\mu}=0.06$ and $\alpha \leq 15^{\circ}$, the highest $C_{l} / C_{d}$ is observed. As the angle of attack increases from $\alpha=20^{\circ}$ to $30^{\circ}$, the $C_{l} / C_{d}$ decreases. At $C_{\mu}=0.13$ and $\alpha \leq 10^{\circ}$, the use of CFJ is not affordable while for $\alpha \geq 15^{\circ}$, a significant $C_{l} / C_{d}$ is obtained because of the significant lift generation. For the other angles, the maximum $C_{l} / C_{d}$ are distinct at each angle of attack. The baseline airfoil result shows the stall occurrence around $\alpha=10^{\circ}$, whereas for the CFJ airfoils results 
with $C_{\mu}=0.05-0.07$ the stall occurs at $\alpha=15^{\circ}$. With further increase in the momentum coefficients, the stall angles increase, and at $C_{\mu}=0.13$ the stall does not occur up to $\alpha=30^{\circ}$. Fig. 10 shows the stall angles versus the different momentum coefficient. A sharp slope is observed from $C_{\mu}=0.09$ to 0.13 .

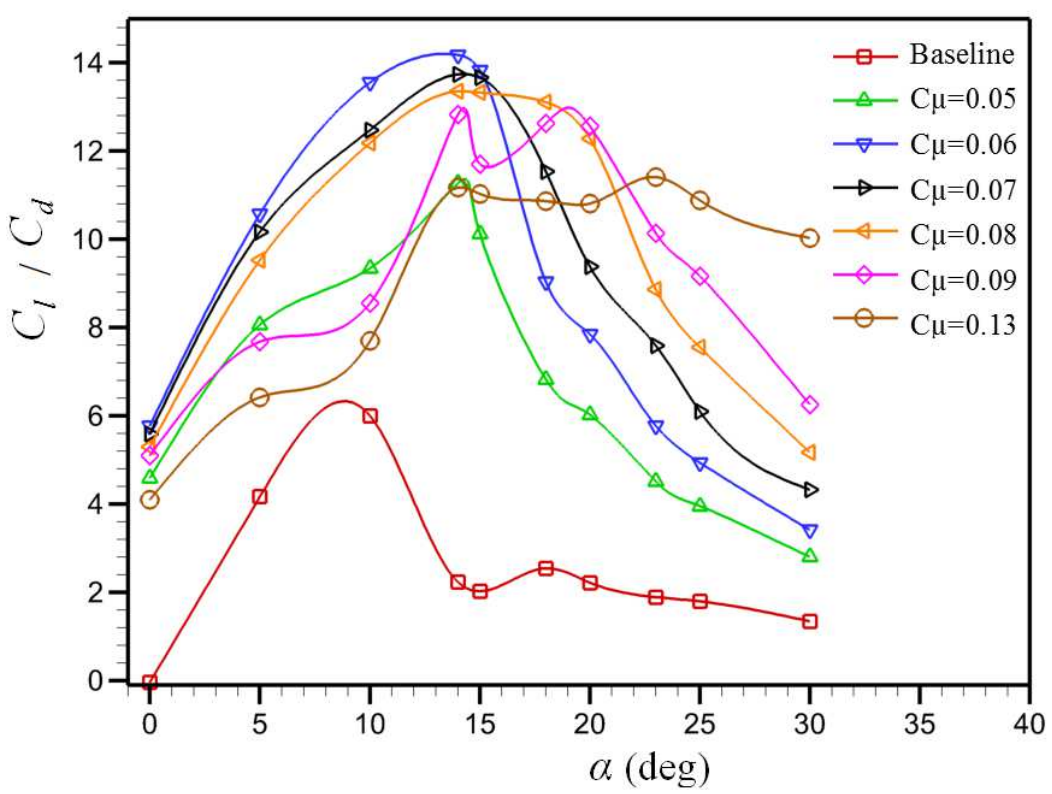

Fig. 9 Comparison of lift to drag coefficients for different $C_{\mu}$ levels.

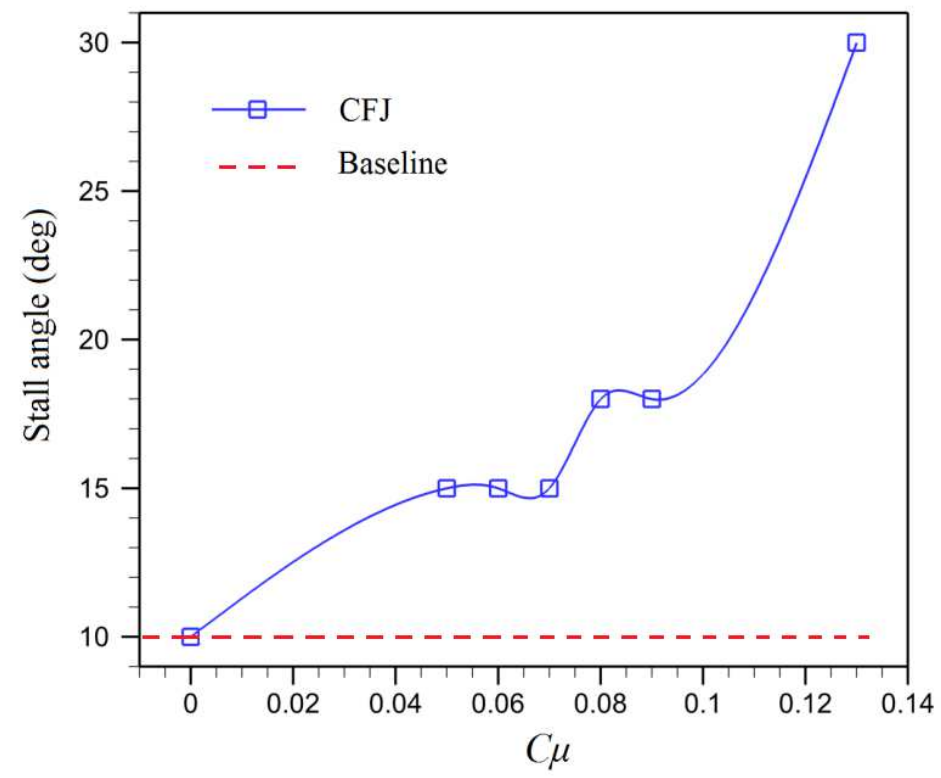

Fig. 10 Variation of stall angles for different $C_{\mu}$ levels. 
Fig. 11 shows the Optimum $C_{\mu}$ corresponding to $\left(C_{l} / C_{d}\right)$ max, for different angles of attack. Within the range of $15^{\circ}<\alpha<23^{\circ}$ by increasing the momentum coefficient, the ratio of the lift to the drag is enhanced, and it makes an increases in the energy consumption of the CFJ. It can also be seen that the CFJ has the highest ratio of the lift to the drag at $14^{\circ}$. It should be noted that the required momentum coefficient at this angle compared to other angels has the smallest value. Fig. $12 \mathrm{a}$ and $12 \mathrm{~b}$ show the velocity profiles for the baseline and CFJ cases with the momentum coefficients $C_{\mu}=0.05$ and 0.09 at $x / c=0.3$ and 0.6 , respectively. In both sections, the boundarylayer momentum of the CFJ cases is significantly increased, compared to the baseline airfoil.

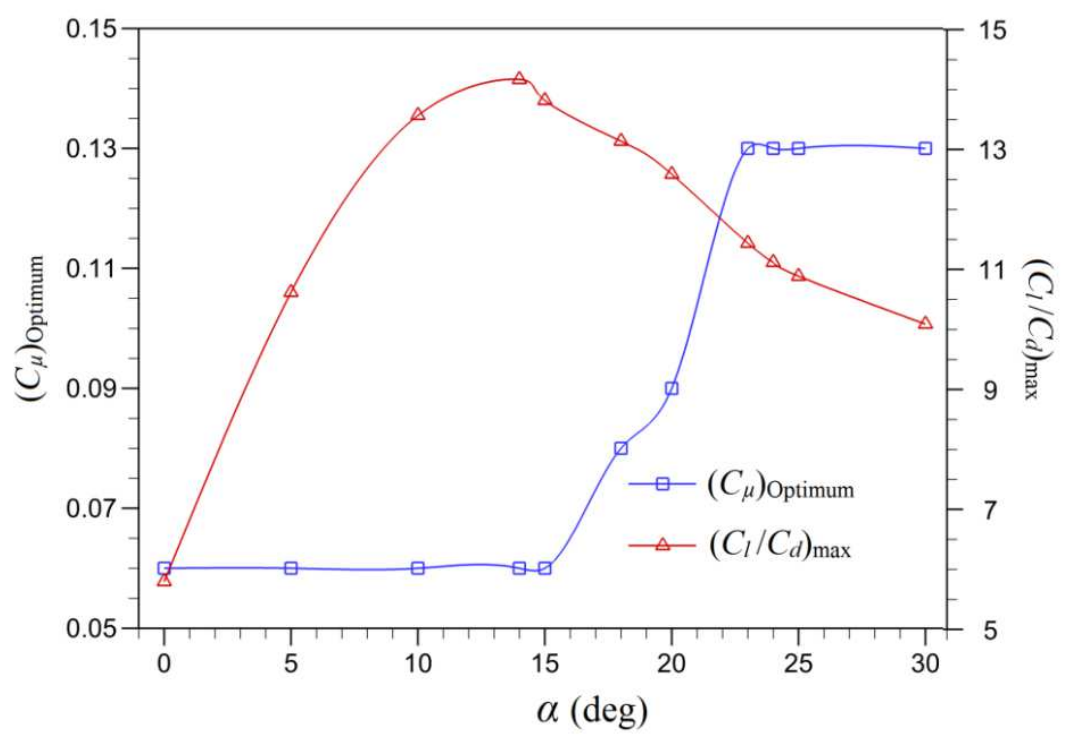

Fig. 11 Optimum $C_{\mu}$ and maximum $C_{l} / C_{d}$ for different Angles of attack. 

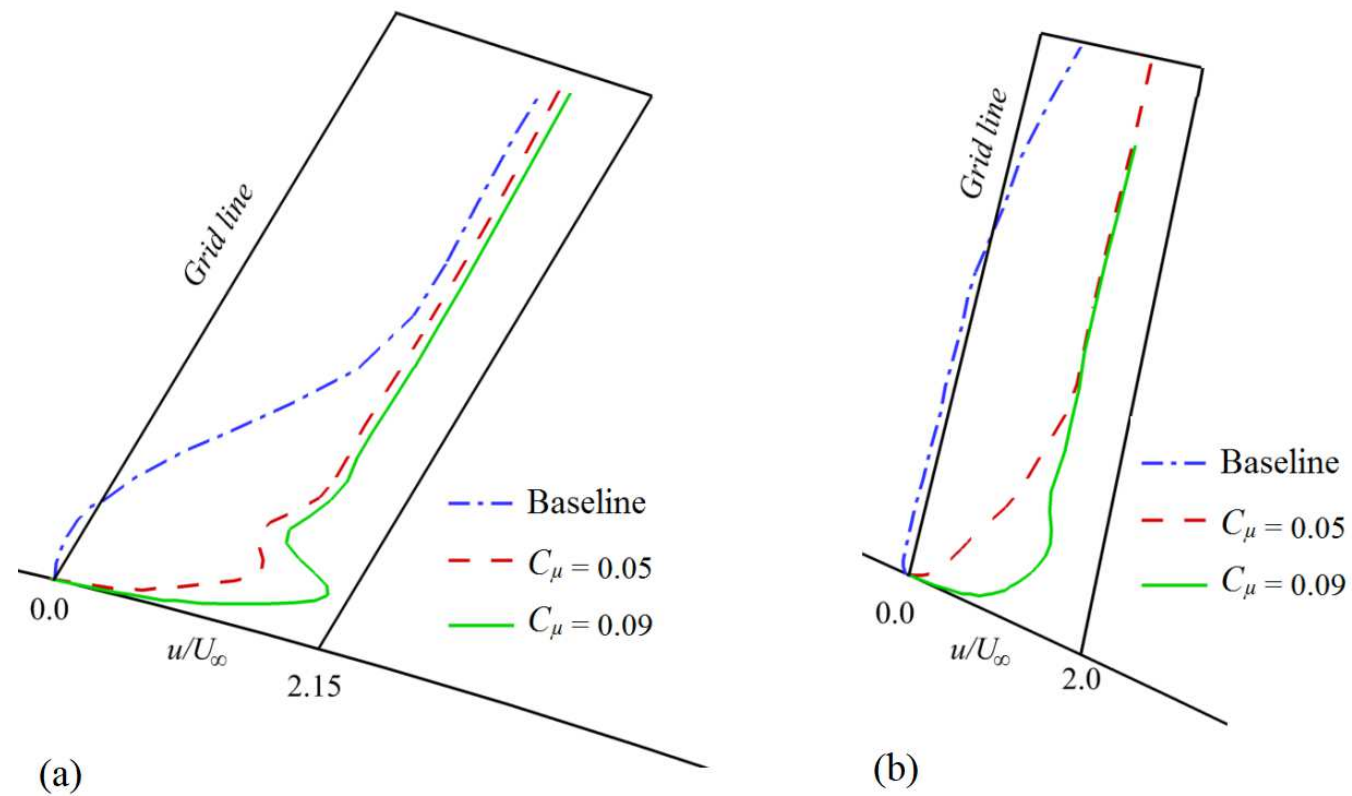

(b)

Fig. 12 Comparison of velocity profiles near the airfoil surface at $\alpha=15^{\circ}$, (a) $x / c=0.3$, (b) $x / c=0.6$.

Table 1 shows the comparison of the maximum lift coefficients and locations of the stall onset between the baseline and CFJ cases. The maximum lift is greatly enhanced by use of the CFJ.

Table 1. Comparison of maximum lift coefficients and locations of stall onset.

\begin{tabular}{ccccc}
\hline Cases & Maximum $C_{l}$ & $\begin{array}{c}\text { Stall angle } \\
(\mathrm{deg})\end{array}$ & $\begin{array}{c}\text { Increment in } C_{L \max } \\
\text { relative to the } \\
\text { baseline (\%) }\end{array}$ & $\begin{array}{c}\text { Increment in stall } \\
\text { angle relative to } \\
\text { the baseline (deg.) }\end{array}$ \\
\hline Baseline & 0.6 & 10 & --- & --- \\
$C_{\mu}=0.05$ & 1.26 & 15 & $110.00 \%$ & 5 \\
$C_{\mu}=0.06$ & 1.76 & 15 & $193.33 \%$ & 5 \\
$C_{\mu}=0.07$ & 1.9 & 15 & $216.67 \%$ & 5 \\
$C_{\mu}=0.08$ & 2.16 & 18 & $260.00 \%$ & 8 \\
$C_{\mu}=0.09$ & 2.25 & 18 & $275.00 \%$ & 8 \\
$C_{\mu}=0.13$ & 3.11 & 30 & $418.33 \%$ & 20 \\
\hline
\end{tabular}




\subsection{Effect of CFJ on the dynamic stall at $R e=1.5 \times 10^{5}$}

Another investigation in this paper is about the effect of CFJ on the dynamic stall phenomenon. The simulation is performed at $k=0.15$ for the baseline airfoil and two CFJ cases with $C_{\mu}=0.05$ and 0.07. By increasing the momentum coefficient, more energy can be transferred into the boundary layer; consequently, the lift coefficient is increased. Fig. 13 shows the lift coefficient curve for the CFJ control cases and the baseline airfoil. As can be seen, the lift coefficient curve for the CFJ case with $C_{\mu}=0.05$ shifts up and is increased, compared to the baseline airfoil, however the stall still occurs and this behavior is almost similar to the baseline airfoil. With increasing the momentum coefficient from 0.05 to 0.07 , the lift coefficient hysteresis loop becomes smaller as awaited. Furthermore, for the case with $C_{\mu}=0.07$, the lift coefficient curve does not present the

stall feature, demonstrating that a stronger jet can fully control the dynamic stall. The amount of the maximum lift coefficient for the baseline airfoil is equal to 1.15 and for the CFJ cases for $C_{\mu}=$ 0.05 and 0.07 is equal to 2.06 and 2.16, respectively. In terms of the drag curves, Fig. 14 shows the CFJ control cases with $C_{\mu}=0.05$ and 0.07 and the baseline airfoil. The maximum drag coefficient for the baseline airfoil and two CFJ cases are 0.54, 0.32 and 0.21 respectively. Therefore, for the case with $C_{\mu}=0.07$ the maximum drag coefficient is decreased by $61 \%$, furthermore, its hysteresis loop becomes smaller and smoother. 


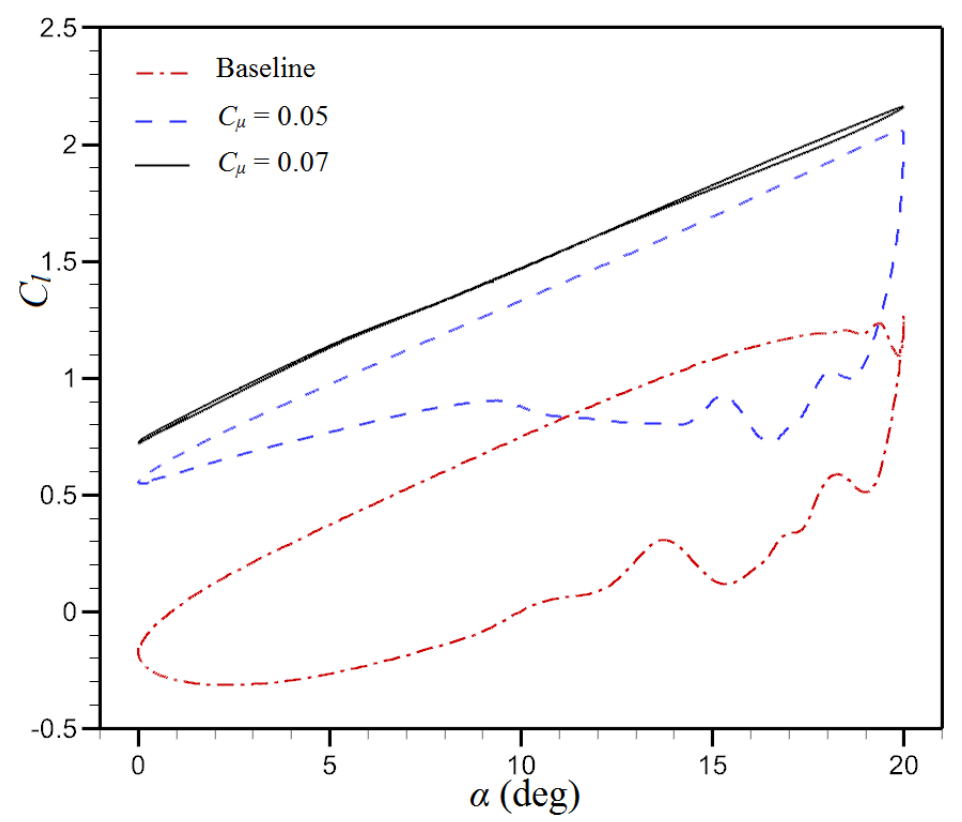

Fig. 13 Comparison of lift coefficients between the CFJ cases and the baseline airfoil.

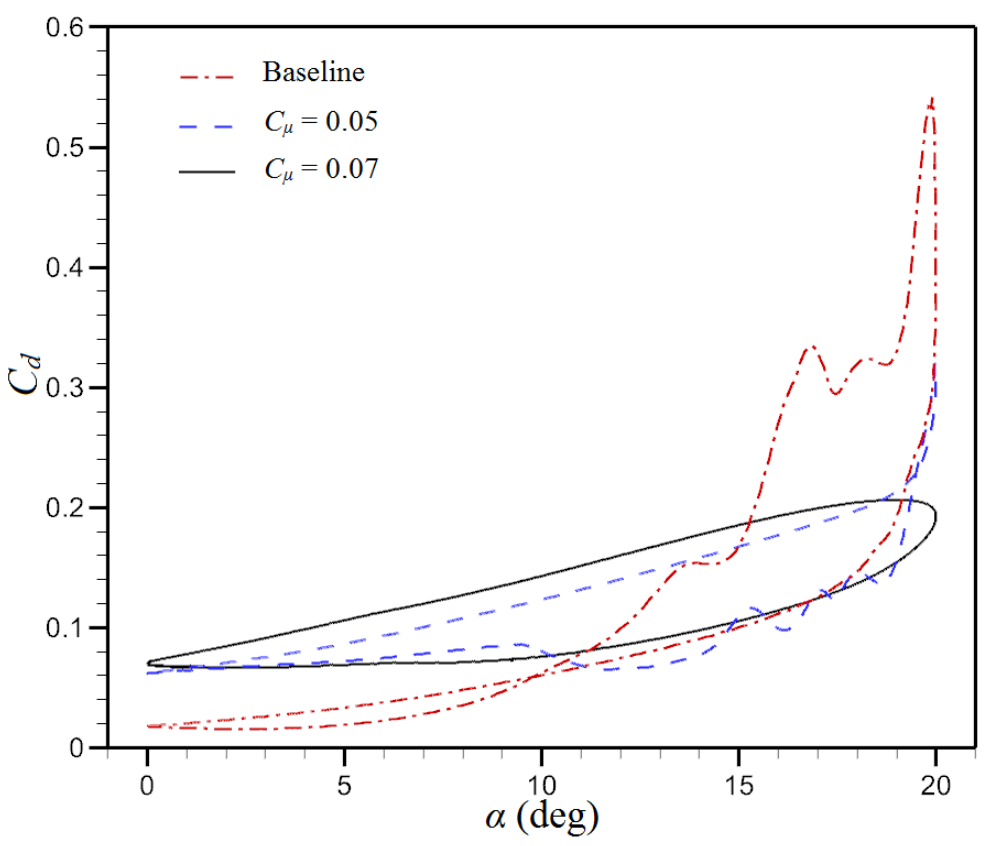

Fig. 14 Comparison of drag coefficients between the CFJ cases and the baseline airfoil.

Table 2 presents the averages of the aerodynamic hysteresis loops for two cases with $C_{\mu}=0.05$ and 0.07 . In order to quantify the enhancement in the lift and the reduction in the drag coefficients 
over a pitch cycle due to CFJ cases, the differences within the area under the $C_{l}$ and $C_{d}$ curves between the control and baseline cases are computed. The resulting values due to the CFJ control are summarized in Table 2. It is observed that the average lift coefficient can be significantly increased by implementing the CFJ, and the average drag coefficient also slightly be increased. Finally, the results at $c_{\mu}=0.07$ show that the relative difference of the lift and drag coefficients $\left(\Delta A_{C_{l}}, \Delta A_{C_{d}}\right)$ are improved compared to the baseline airfoil.

Table2. Effects of CFJ control compared to the baseline $(k=0.15)$.

\begin{tabular}{cccc}
\hline coefficient & Baseline & $c_{\mu}=0.05$ & $c_{\mu}=0.07$ \\
\hline$C_{l, \text { ave }}$ & 0.36 & 1.08 & 1.44 \\
$C_{d, \text { ave }}$ & 0.099 & 0.11 & 0.115 \\
$C_{l, \text { ave }} / C_{d, \text { ave }}$ & 3.64 & 9.82 & 12.52 \\
$\Delta A_{C_{l}}$ & - & $200 \% \uparrow$ & $300 \% \uparrow$ \\
$\Delta A_{C_{d}}$ & - & $12 \% \uparrow$ & $16 \% \downarrow$ \\
\hline
\end{tabular}

\subsection{Effects of Reynolds number}

The effect of the CFJ method on the aerodynamic performance of the airfoil is studied at five Reynolds numbers from $0.5 \times 10^{5}$ to $3 \times 10^{5}$. This evaluation is carried out for different jet momentum coefficients of $0.03,0.06,0.09$, and 0.13 in a range of angle of attack from $0^{\circ}$ to $20^{\circ}$.

Fig. 15 depicts the performance of the lift coefficient for the CFJ airfoil in comparison with the baseline airfoil at different Reynolds numbers and momentum coefficients. The present results indicate that at these Reynolds numbers, use of flow control is of more importance than that for other cases where its results have the best performance among all angles of attack at different momentum coefficients. Furthermore, at all investigated Reynolds numbers, the angle of $15^{\circ}$ offers the best performance of lift coefficient for the CFJ airfoil compared to the baseline airfoil. The 
stall occurs at lower angles of attack for the baseline airfoil while it is delayed for the CFJ airfoil. This is the reason for the improvement of airfoil performance regarding the lift coefficient at the angle of $15^{\circ}$. In the baseline airfoil, the lift coefficient is reduced after the occurrence of the stall phenomenon that can be seen at the angle of $15^{\circ}$, while by applying the CFJ the stall phenomenon does not occur until this angle of attack. More enhanced lift coefficient is achieved compared to the baseline airfoil.
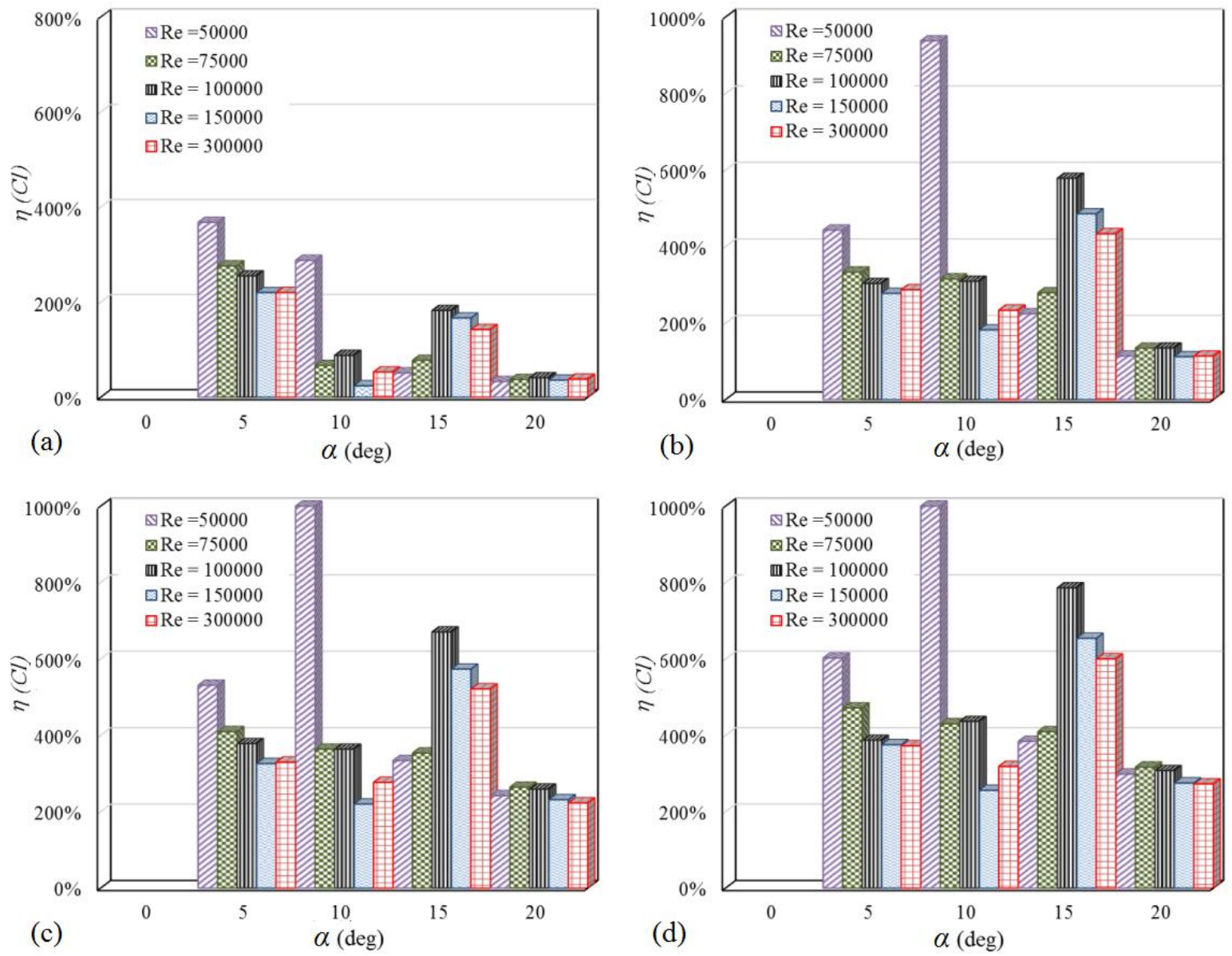

Fig. 15 Comparison of the performance of the lift coefficients as a function of angle of attack for different Reynolds numbers at (a) $C_{\mu}=0.03$, (b) $C_{\mu}=0.06$, (c) $C_{\mu}=0.09$, (d) $C_{\mu}=0.13$. 
Fig. 16 shows the performance of the drag coefficient for the CFJ at different Reynolds numbers and momentum coefficients. In most cases, by increasing the Reynolds number the value of the drag coefficient for CFJ airfoil increases more than that for the baseline airfoil. Furthermore, in most cases, the drag coefficient for the CFJ airfoil at Reynolds number of 50000 increases by a lower percentage.
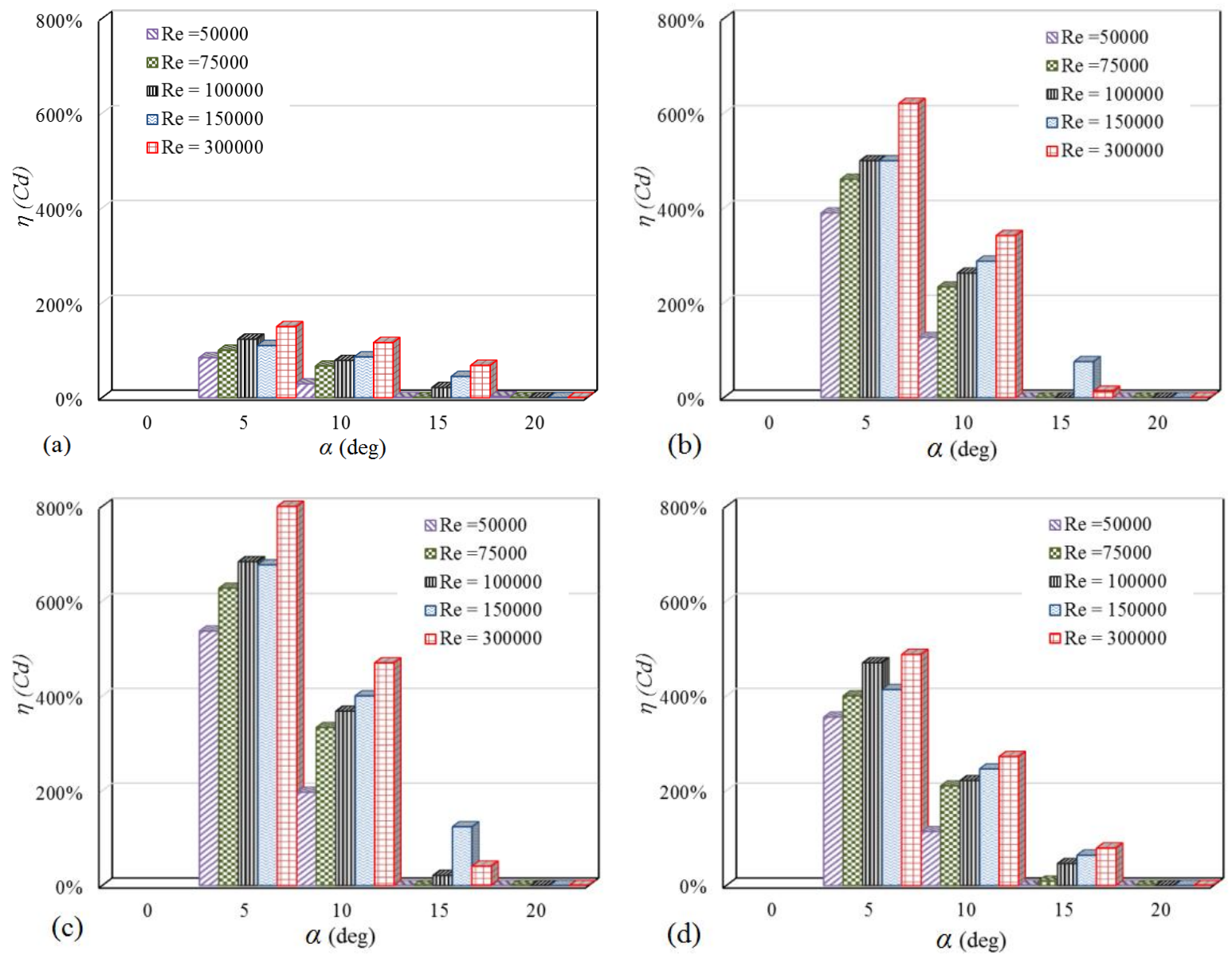

Fig. 16 Comparison of the performance of the drag coefficients as a function of angle of attack for different Reynolds numbers at (a) $C_{\mu}=0.03$, (b) $C_{\mu}=0.06$, (c) $C_{\mu}=0.09$, (d) $C_{\mu}=0.13$.

In addition, the performance of the lift to drag coefficient for the CFJ at different Reynolds numbers and momentum coefficients are calculate as shown in Fig. 17. The most enhancements 
and the best performance of the CFJ airfoil, compared to the baseline airfoil, is observed at the Reynolds number of $0.5 \times 10^{5}$, particularly at lower angles of attack. In other cases, the optimum lift to drag ratio for the $\mathrm{CFJ}$ airfoil is observed at $\alpha=15^{\circ}$. At this angle of attack, although the drag coefficient of the CFJ airfoil is increased compared to the baseline airfoil, there is a more significant increase in the lift coefficient. Therefore, the lift to drag ratio is enhanced that can be attributed to the absence or delay of the stall phenomenon. By occurrence of the stall phenomenon in the baseline airfoil in the vicinity of this angle, the lift and drag coefficients are substantially reduced and increased, respectively. Applying the flow control prohibits the stall and there would be a great enhancement within the range of the stall angles and after them.

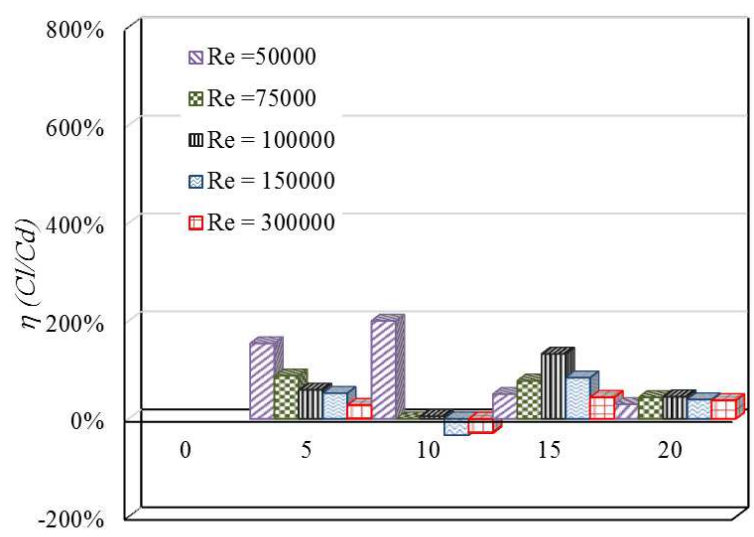

(a)

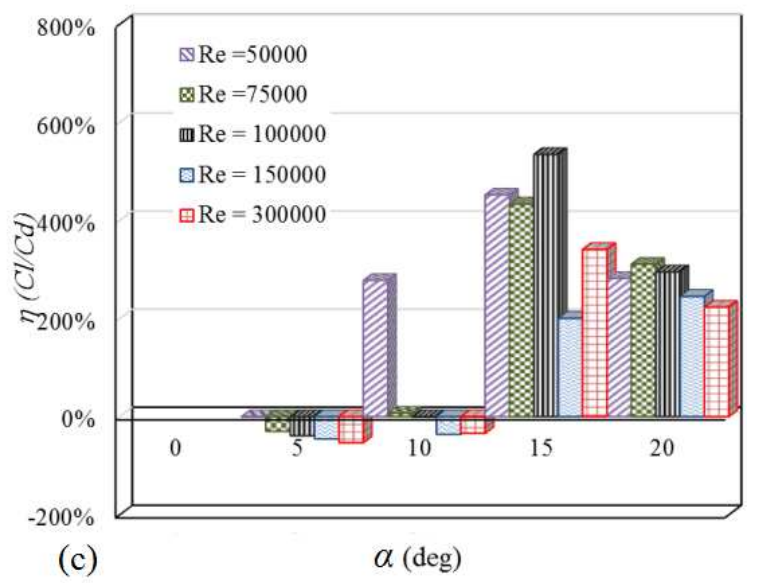

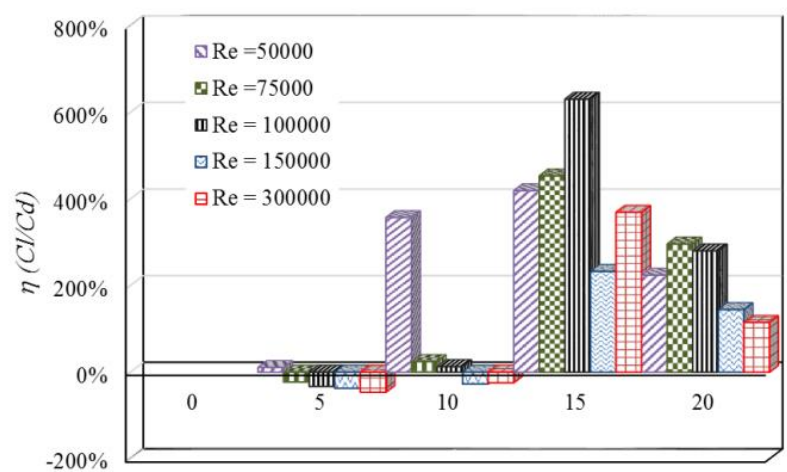

(b)

$\alpha(\mathrm{deg})$

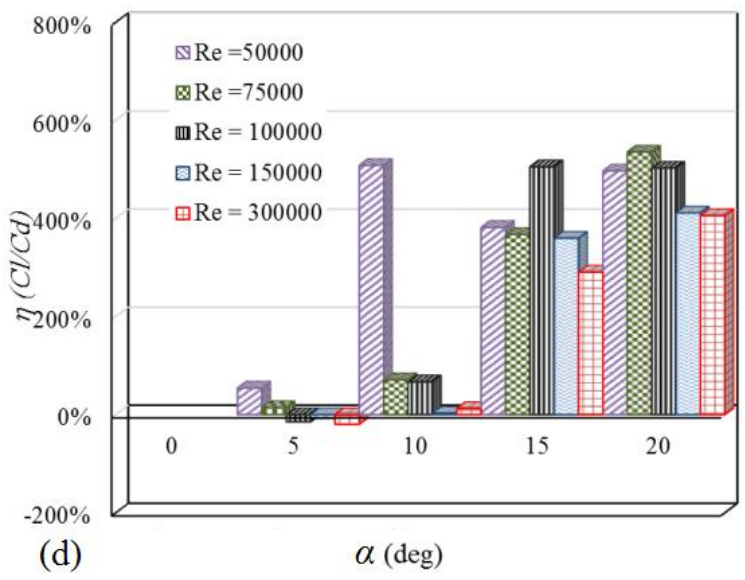

Fig. 17 Comparison of the performance of the lift to drag coefficients as a function of angle of attack for different Reynolds numbers at (a) $C_{\mu}=0.03$, (b) $C_{\mu}=0.06$, (c) $C_{\mu}=0.09$, (d) $C_{\mu}=0.13$. 


\section{Conclusions}

In this paper, a numerical study was conducted to investigate the effect of Co-Flow Jet (CFJ) on the stall and the flow separation of the NACA 0024 airfoil at different Reynolds number from 0.5 $\times 10^{5}$ to $3 \times 10^{5}$. The CFJ control, involved two slots on the suction surface of the airfoil, an injection slot near the leading edge, and a suction slot near the trailing edge. For this investigation, an in-house computer code based on the Reynolds-averaged Navier-Stokes equations, twodimensional, incompressible, and unsteady with the $S S T-k-\omega$ turbulence model was prepared. The solver was validated by comparing with the previous experiment results and the comparisons showed the fairly good agreement. In the present study, the performance of the CFJ control was investigated by implementing the CFJ control at several momentum coefficients and compared the results with the baseline airfoil. Furthermore, the effects of this flow control on the dynamic stall at two momentum coefficients were studied. The conclusions for $\operatorname{Re}=1.5 \times 10^{5}$ are as follows:

(1) The CFJ airfoils compared to the baseline airfoil had a dramatic gain in the lift coefficients and caused the stall occurred at the higher angles of attack maintained with higher values of $C_{\mu}$.

(2) For all the CFJ airfoils with various momentum coefficients, the stall angles and maximum lift coefficients were increased with raising the momentum coefficients.

(3) For the angles of attack lower than the stall angles, by increasing the momentum coefficient, no improvement was seen compared to the lower momentum coefficients and the trend had almost been stable.

(4) The baseline airfoil result showed the stall occurring around $\alpha=10^{\circ}$, whereas the CFJ airfoils results for $C_{\mu}=0.05-0.07$ showed the stall occurring at $\alpha=15^{\circ}$. With further increase in the momentum coefficients, the stall angles were increased, and at $C_{\mu}=0.13$ the stall was not occurred until $\alpha=30^{\circ}$. 
(5) by increasing the momentum coefficient, the drag coefficient increased compared to the baseline airfoil, while for higher angles, increasing the momentum coefficient led to reduction in the flow separation zone and consequently, the drag coefficient decreased compared to the baseline airfoil.

(6) For $\alpha \leq 15^{\circ}, C_{l} / C_{d}$ was maximized at $C_{\mu}=0.06$.

(7) The CFJ had the highest ratio of the lift to the drag at $\alpha=14^{\circ}$ and $C_{\mu}=0.06$.

(8) For the dynamic stall case, with increasing the momentum coefficient from 0.05 to 0.07 , the lift coefficient hysteresis loop became smaller. Furthermore, for the case with $C_{\mu}=0.07$, the lift coefficient curve did not present the stall feature, demonstrating that a stronger jet could fully control the dynamic stall.

(9) Investigation of the Reynolds number effect indicated that by applying the CFJ, the highest enhancement in the aerodynamic coefficients was observed at the Reynolds numbers lower than $10^{5}$. The separated flow did not reattach to the surface at the Reynolds numbers lower than $10^{5}$ that could be yield a great reduction in the aerodynamic performance.

\section{Declarations}

\section{Availability of data and materials}

The datasets used and/or analysed during the current study are available from the corresponding author on reasonable request.

\section{Competing interests}

The authors declare no competing financial interests.

\section{Funding}

Not applicable. 


\section{Authors' contributions}

SY prepared the figures and analysed the article's data. ES carried out the numerical simulation and developed the solver's computer code. AS found the mathematical models and formulations.

\section{Acknowledgements}

Not applicable.

\section{References}

[1] M. SaqibHameed and S. KamranAfaq, "Design and analysis of a straight bladed vertical axis wind turbine blade using analytical and numerical techniques," Ocean Engineering, vol. 57, pp. 248-255, 2013, doi: 10.1016/j.oceaneng.2012.09.007.

[2] S. Yarusevych, P. E. Sullivan, and J. G. Kawall, "Coherent structures in an airfoil boundary layer and wake at low Reynolds numbers," Physics of Fluids, vol. 18, no. 4, p. 044101, 2006, doi: 10.1063/1.2187069.

[3] P. B. S. Lissaman, "Low-Reynolds-Number Airfoils," Annual Review of Fluid Mechanics, vol. 15, no. 1, pp. 223-239, 1983, doi: 10.1146/annurev.fl.15.010183.001255.

[4] T. J. Mueller and J. D. DeLaurier, "Aerodynamics Ofsmallvehicles," Annual Review of Fluid Mechanics, vol. 35, no. 1, pp. 89-111, 2003, doi: 10.1146/annurev.fluid.35.101101.161102.

[5] S. Yarusevych, J. G. Kawall, and P. E. Sullivan, "Airfoil Performance at Low Reynolds Numbers in the Presence of Periodic Disturbances," Journal of Fluids Engineering, vol. 128, no. 3, p. 587, 2006, doi: 10.1115/1.2175165.

[6] D. N. Srinath and S. Mittal, "Optimal airfoil shapes for low Reynolds number flows," International Journal for Numerical Methods in Fluids, vol. 61, no. 4, pp. 355-381, 2009, doi: 10.1002/fld.1960.

[7] E. Salimipour, "A modification of the k-kL- $\omega$ turbulence model for simulation of short and long separation bubbles," Computers \& Fluids, vol. 181, pp. 67-76, 2019, doi: 10.1016/j.compfluid.2019.01.003.

[8] Ok-Sok Gim and G.-W. Lee, "Flow characteristics and tip vortex formation around a NACA 0018 foil with anendplate," Ocean Engineering, vol. 60, pp. 28-38, 2013, doi: 10.1016/j.oceaneng.2012.12.009.

[9] E. Salimipour and S. Yazdani, "Improvement of aerodynamic performance of an offshore wind turbine blade by moving surface mechanism," Ocean Engineering, vol. 195, 2020, doi: 10.1016/j.oceaneng.2019.106710.

[10] a. s. abbasi and S. Yazdani, "A Numerical Investigation of Synthetic Jet Effect on Dynamic Stall Control of Oscillating Airfoil \%J Scientia Iranica," vol. in press., pp. -, 2019, doi: 10.24200/sci.2019.52743.2870.

[11] D. Velasco, O. López Mejia, and S. Laín, "Numerical simulations of active flow control with synthetic jets in a Darrieus turbine," Renewable Energy, vol. 113, pp. 129-140, 2017, doi: 10.1016/j.renene.2017.05.075. 
[12] A. S. Shehata, Q. Xiao, K. M. Saqr, A. Naguib, and D. Alexander, "Passive flow control for aerodynamic performance enhancement of airfoil with its application in Wells turbine - Under oscillating flow condition," Ocean Engineering, vol. 136, pp. 31-53, 2017, doi: 10.1016/j.oceaneng.2017.03.010.

[13] Ahmet Ziya Saydam, Serhan Gokcay, and M. Insel, "CFD based vortex generator design and fullscale testing for wake non-uniformity reduction," Ocean Engineering, vol. 153, pp. 282-296, 2018, doi: 10.1016/j.oceaneng.2018.01.097.

[14] E. Salimipour and A. Salimipour, "Power minimization and vortex shedding elimination of a circular cylinder by moving surface mechanism," Ocean Engineering, vol. 189, 2019, doi: 10.1016/j.oceaneng.2019.106408.

[15] A. Khoshnevis, S. Yazdani, and E. Saimipour, "Analysis of co-flow jet effects on airfoil at moderate Reynolds numbers," Journal of Theoretical and Applied Mechanics, vol. 58, no. 3, pp. 685-695, 2020, doi: 10.15632/jtam-pl/122266.

[16] A. Bak Khoshnevis, S. Yazdani, and E. Salimipour, "Effects of CFJ flow control on aerodynamic performance of symmetric NACA airfoils," Journal of Turbulence, vol. 21, no. 12, pp. 704-721, 2020, doi: 10.1080/14685248.2020.1845911.

[17] G. Zha, C. Paxton, C. A. Conley, A. Wells, and B. F. Carroll, "Effect of Injection Slot Size on the Performance of Coflow Jet Airfoil," Journal of Aircraft, vol. 43, no. 4, pp. 987-995, 2006, doi: 10.2514/1.16999.

[18] G. Zha and C. Paxton, "A novel airfoil circulation augment flow control method using co-flow jet," presented at the 2nd AIAA Flow Control Conference, Portland, OR, United States, 2004.

[19] G. Zha, W. Gao, and C. D. Paxton, "Jet Effects on Coflow Jet Airfoil Performance," AIAA Journal, vol. 45, no. 6, pp. 1222-1231, 2007, doi: 10.2514/1.23995.

[20] G. Zha and W. Gao, "Analysis of jet effects on co-flow jet airfoil performance with integrated propulsion system," presented at the 44th AIAA Aerospace Sciences Meeting Reno, NV, United States, 2006.

[21] A. Wells, C. Conely, B. Carroll, Paxton, C., , and G. C. Zha, "Velocity Field for an Airfoil with Co-Flow Jet Flow Control," presented at the 44th AIAA Aerospace Sciences Meeting and Exhibit, Reno, Nevada, 9 - 12 January 2006, 2006.

[22] T. L. Chng, A. Rachman, H. M. Tsai, and G.-C. Zha, "Flow Control of an Airfoil via Injection and Suction," Journal of Aircraft, vol. 46, no. 1, pp. 291-300, 2009, doi: 10.2514/1.38394.

[23] R. Abinav, N. R. Nair, P. Sravan, P. Kumar, and S. R. Nagaraja, "CFD Analysis of Co Flow Jet Airfoil," Indian Journal of Science and Technology, vol. 9, no. 45, 2016, doi: 10.17485/ijst/2016/v9i45/104686.

[24] H.-Y. Xu, S.-L. Xing, and Z.-Y. Ye, "Numerical study of the S809 airfoil aerodynamic performance using a co-flow jet active control concept," Journal of Renewable and Sustainable Energy, vol. 7, no. 2, p. 023131, 2015, doi: 10.1063/1.4919013.

[25] S. Ethiraj, "Aerodynamic performance analysis of a co-flow jet aerfoil using CFD," International Research Journal of Engineering and Technology, vol. 4, no. 7, 2017.

[26] S. L. Siddanathi, "Application of Co-Flow Jet Concept to Aircraft Lift Increase," International Journal of Advances in Mechanical \& Automobile Engineering, vol. 3, no. 1, 2016, doi: 10.15242/ijamae.iae0116206. 
[27] Morteza Mirhosseini and A. B. Khoshnevis, "Effect of Adverse Pressure Gradient on a Fluctuating Velocity over the Co-Flow Jet Airfoil," International Journal of Mechanical and Mechatronics Engineering, vol. 10, 2016.

[28] Md. Amzad Hossain, Md. Nizam Uddin, Md. Rasedul Islam and, and M. Mashud, "Enhancement of Aerodynamic Properties of an Airfoil by Co Flow Jet (CFJ) Flow," American Journal of Engineering Research, vol. 4, no. 1, 2015.

[29] A. Lefebvre and G. Zha, "Numerical Simulation of Pitching Airfoil Performance Enhancement Using Co-Flow Jet Flow Control," presented at the 31st AIAA Applied Aerodynamics Conference, 2013.

[30] H.-Y. Xu, C.-L. Qiao, and Z.-Y. Ye, "Dynamic Stall Control on the Wind Turbine Airfoil via a CoFlow Jet," Energies, vol. 9, no. 6, 2016, doi: 10.3390/en9060429.

[31] M. Ghalambaz, S. A. M. Mehryan, A. Tahmasebi, and A. Hajjar, "Non-Newtonian phase-change heat transfer of nano-enhanced octadecane with mesoporous silica particles in a tilted enclosure using a deformed mesh technique," Applied Mathematical Modelling, vol. 85, pp. 318-337, 2020, doi: 10.1016/j.apm.2020.03.046.

[32] E. Salimipour, "A numerical study on the fluid flow and heat transfer from a horizontal circular cylinder under mixed convection," International Journal of Heat and Mass Transfer, vol. 131, pp. 365-374, 2019, doi: 10.1016/j.ijheatmasstransfer.2018.11.084.

[33] R. G. Rajagopalan and A. D. Lestari, "RK-SIMPLER: Explicit Time-Accurate Algorithm for Incompressible Flows," AIAA Journal, vol. 54, no. 2, pp. 616-624, 2016, doi: 10.2514/1.j054030.

[34] H. L. Stone, "Iterative Solution of Implicit Approximations of Multidimensional Partial Differential Equations," SIAM Journal on Numerical Analysis, vol. 5, no. 3, pp. 530-558, 1968, doi: $10.1137 / 0705044$.

[35] Seyed M. Hashem Zadeh, S. A. M. Mehryan, M. S. Islam, and M. Ghalambaz, "Irreversibility analysis of thermally driven flow of a water-based suspension with dispersed nano-sized capsules of phase change material," International Journal of Heat and Mass Transfer, vol. 155, 2020, doi: 10.1016/j.ijheatmasstransfer.2020.119796. 